Journal of Computer Science 4 (4): 315-319, 2008

ISSN 1549-3636

(C) 2008 Science Publications

\title{
Effect of Information and Communication Technologies (ICT) on Non-Industrial Countries-Digital Divide Model
}

\author{
Mahmoud Z. Iskandarani \\ Faculty of Science and Information Technology, \\ Al-Zaytoonah Private University of Jordan, P.O. Box 911597, Post Code: 11191, Jordan
}

\begin{abstract}
The influence of information and communication technology on the collective activities and interests of a broad range of people was discussed and analyzed. The important consequence of ICT called digital divide was mathematically modeled and the results analyzed. The closed loop feedback model proved the need for a society to be educationally, culturally, economically and politically ready to integrate and implement new technologies into its infrastructure.
\end{abstract}

Key words: Knowledge society, economics, information technology, education, management, digital divide, $\mathrm{HCI}$

\section{INTRODUCTION}

The influence of information technology on social practices has mainly been to the effect of making information about them more accessible. The most relevant question though is whether the developments in information technologies have influenced the continuity of social attitudes, customs or institutions ${ }^{[1-6]}$. Social attitudes have changed with the effect that citizens of a society now expect the various elements of that society to be better informed than previously. They also expect to be able to access more information about a specific product, service or organization so that they can make informed decisions with regard to their interactions with that entity. The word institutions can incorporate a wide variety of organizations such as governments, commercial businesses, news and media organizations and educational organizations.

Developments in information technology have helped governments to improve their services to their citizens. Advances in Database technology for example have enabled the governments of various countries to collate and monitor statistical information that they can use to combat fraud, manage the economy in a better way. The advances in information technology have heavily influenced commercial businesses in several ways. The most important role of information technology in a commercial business is to provide a commercial advantage. Advances such as computer aided design; relational database technologies, spreadsheets and word processing software all provide a commercial benefit to the business, as automation of manufacturing processes and as different businesses compete with each other, the commercial advantage one can have over another may depend primarily on its use of information technologies. For example being able to extract information as to what the customer really wants and how to provide for that want can provide a significant advantage. This extraction of information is facilitated and indeed made possible by the technology used to store and manipulate this information. As the hardware and software mechanisms used to store and manipulate the information become more sophisticated and quicker the business can utilize its stored information to maximize its commercial advantage ${ }^{[7-8]}$.

The use of information technology to monitor a businesses performance can also enable the business to highlight areas where they are not making the most use of their resources. The use of information technologies can also increase the businesses income through advertising in the various available forums. Due to the nature of news and media organizations, the information technologies have particular relevance to them. As noted earlier Information Technology is the technology used to store, manipulate, distribute or create information. News and media organizations are intimately acquainted with each of these elements of information technology.

Developments such as the Internet and satellite television have created new medium and audiences through which and to which these organizations can disseminate their information. The relative cheapness of being able to publish information on the Internet means that virtually anyone can publish information accessible anywhere in the world. As information technology has developed over the past years, educational establishments have been influenced in various ways. The most obvious example has been the introduction of 
information technology related courses. These courses are introduced to try to satisfy the demand that society has for qualified people to develop these information technologies ${ }^{[13-17]}$.

The developments that have occurred in information technology have also had other influences on educational establishments. Educational organizations have a goal to distribute information from a source to the student. The processes by which educational establishments distribute information have become increasingly diverse and the effectiveness of the process has also improved.

The distribution of information is not the only concern of educational establishments. For example one of the aims of Universities is to create information. This creation is done by research. Information technologies have enabled researchers to access a wider source of information than previously available through such technologies as the Internet. The Internet and other related technologies such as electronic mail also enable collaborative projects to be undertaken between geographically distant groups ${ }^{[18-21]}$.

People are only key players in the information society if they have been well educated, which gives them with the informational abilities to survive in a new and globalized economy. Information is a key factor to any development process. The Internet as an information and communication medium has come to play a major role in the distribution of information. Information and Communication Technologies (ICTs) have changed the way information is stored, disseminated and processed. Information is central in areas of social, economic and political activities. Even though the Internet has brought about freedom, productivity and communication, its uneven distribution and access has led to what he refers to as a Digital Divide. Exclusion leads to a fundamental cleavage to already existing inequality and social exclusion ${ }^{[22]}$. In this study effect of ICT and its effect on diverse sectors of societies is presented, with particular emphasis on Digital Divide phenomenon.

\section{DIGITAL DIVIDE}

Background: Developments in the Communications field show how the knowledge gaps between the information-rich and the information-poor have deepened over time thereby excluding certain parts of the world from enjoying the fruits of what is referred to as a Global Village. The changing economic, social and political situations have a direct impact on the individual society members and the different business sectors, where organizations have to effectively use and trade in information in order to survive. With the expansion of the Internet, a medium deemed by many as a tool that would enable different parts of the world to interact, carry out business and live side by side in the virtual space, proved to be mainly true for the Western world that has had access to information technology for decades and therefore developed skills for processing information. The provision of information technology does not translate into attainment of development. In order to work towards development, skills in processing information are a necessity. Given the information gap that exists in the world today, issues concerning the information imbalance need to be seriously and genuinely addressed in order to fight poverty, the growing Digital Divide and to achieve development ${ }^{[23]}$.

Communication specialists view development as knowledge based. Development is achieved through the acquisition of information, education and skills that empower individuals to make choices and exercise control over their environments in order to work for the improvement of existing conditions. Development must be based on economic independence, co-operation and fair competition between nation-states.

Affected areas: Internet diffusion in developing countries is said to deepen the digital divide since it is concentrated in urban centers, around global activities, among highly educated groups who in turn are connected to global networks. Most regions and people are left out. Developing countries lack telecommunication infrastructure, Internet service and content providers and strategies to deal with these problems. Information, education, science and technology the most critical sources of value in the Internet-based economy. Exclusion from the Internetbased economy means little chance for any country to cater for its own developmental needs. The Internetbased logic of production, competition and management is a prerequisite for prosperity, freedom and autonomy. The regions that previously participated in the Industrial-era and benefited from it are the ones reaping off the fruits of current technology like the Internet. This overall intellectual transformation is excluding poor nations that are too busy grappling with enormous social problems like illiteracy, poverty and poor health. Today, we have countries in the periphery that are still struggling to put in place basic communication infrastructure. While industrialized countries are worrying about issues of mergers, transnational data flows, computers, censorship, privacy and employment in cultural industries, some of the Peripheral Countries have not started participating fully in the information age ${ }^{[24-25]}$. 
Development must be based on economic independence, co-operation and fair competition between nations. To ease access to the Internet there has to be a liberalization of international gateways, creation of national and regional Internet Exchange that regional Internet traffic does not need to pass through Europe and North America. Low-cost wireless broadband technologies should be made available and licensing practices should create an environment, which attracts local and foreign investment.

The nature of education should prepare students to become future workers in a fast changing job market. Access to Internet and the World Wide Web would enable students to take advantage of the information superhighways. Constant learning and skills upgrading is a necessity in order to cope. Individuals must be equipped with knowledge that will help them transform ideas into serious business ventures. In order for a nation to become a winning nation, it must have an education system designed for its social and economic needs. Primary and Secondary education is of paramount importance. In order for information technology and knowledge to be appreciated and integrated into less fortunate societies, the majority of people need access to computers and the Internet. The limited number of Internet clients is due to the fact that computers are expensive, low levels of computer knowledge, poor educational institutions and high transmission cost for telephone usage ${ }^{[9-12]}$.

To participate in the new e-business economy where all key business operations from purchasing, sales, to managing are conducted over a computerized network, society members need to adapt to its needs. The e-economy cannot function without workers that are able to navigate, both technically and in terms of content, the rich content of information, organize it, focus it and transform it into specific knowledge, appropriate for the task and purpose of the work process. This kind of labor must be highly educated and able to take initiatives. In order to be this confident, workers must have developed the skills of learning how to learn, where a person takes the initiative to seek new information, know where to look for it, understand it and how to use it. For an underdeveloped country that wishes to embrace ICTs, there is need to plan and budget for lifelong education for all. This is because the information society is going to lead to a knowledge society where individuals as well as institutions will be valued according to what and how much they know. This means that there will be need to acquire new knowledge and skills in order to understand and operate ICTs in an efficient manner. The speed at which ICTs change will require the type of learning that will continuously up-date the individuals with equally new skills.

Digital divide model: Transformations of the $21 \mathrm{st}$ Century have brought about immense organizational changes. The economic environment caused by globalization and technology have forced organizations around the world to make significant transformations in order to competitively survive, adapt and achieve success. Knowledge, information and ideas are now replacing traditional key resources of business like capital, personnel and facilities. Organizations are now restructuring and thereby creating global networks. Virtual organizations are linked by information technology to share skills, costs and access to one another's markets. In today's networked environment, business organizations need to conform to the Internet based technology, which is an effective tool in relating to customers and suppliers. The Internet allows scalability in terms of local and global networks. It further allows interactivity, management of flexibility, branding and customization in a networked business. Using the Internet, businesses are adopting networks as their organizational forms. The interactive and networked relationship between producers, customers and service providers brings about cost reduction, quality and efficiency. Electronic trading is now the core of the financial market place. It has created greater interdependence of global markets. To cope with the challenging environment, organizations need to become learning organizations. Profits and products are based on effective and continual learning. It is the capacity to learn that enables organizations to deal with change dynamics.

Company operations are more and more being automated and customized. Information technology forms the basis of most products and services. Globalization has caused a convergence of economic and social forces, interest and commitments, values and tastes and challenges and opportunities. Knowledge and expertise is the base of organizations' culture, traditions, technology, operations, systems and procedures.

It is knowledge that increases the employees' abilities to produce quality products and services. A changing environment requires an up-date of products and services to suite the customers tastes, change systems and structures and to solve problems. The best ICT effect is represented by the variable input will be subject to various influences, resulting in an affected society and certain deviation denoted by the variable output. Such deviation is computed as follows: 


$$
\text { Input }=\mathrm{e}+\sigma \cdot \text { Output }
$$

where, $\sigma$ represents the needed actions to sustain best result and e is the error or difference:

$$
\text { Output }=\varepsilon \cdot e
$$

where, $\varepsilon$ represents the various ICT influences affecting a society within a specified period:

$$
\left(\frac{\text { Output }}{\text { Input }}\right)=\left(\frac{\varepsilon}{1+\varepsilon . \sigma}\right)=\mathrm{k}
$$

\section{k: ICT Ready Coefficient}

\section{RESULTS AND DISCUSSION}

It is clear from Table 1 that the main controlling factor is the ICT time limited action $(\varepsilon)$ over the timefree action $(\sigma)$, such that whenever $\varepsilon$ approaches zero or negligible value in terms of allowed time for a society to adjust to ICT influences by equipping itself with the right facilities, the over all reject, resistance, fear, inability to change will also approach zero. In other words, when there is no ICT influence or presence, there is no need for any actions to sustain something that does not exist $(\varepsilon \rightarrow 0, \sigma \rightarrow 0)$, or if an ICT effect is
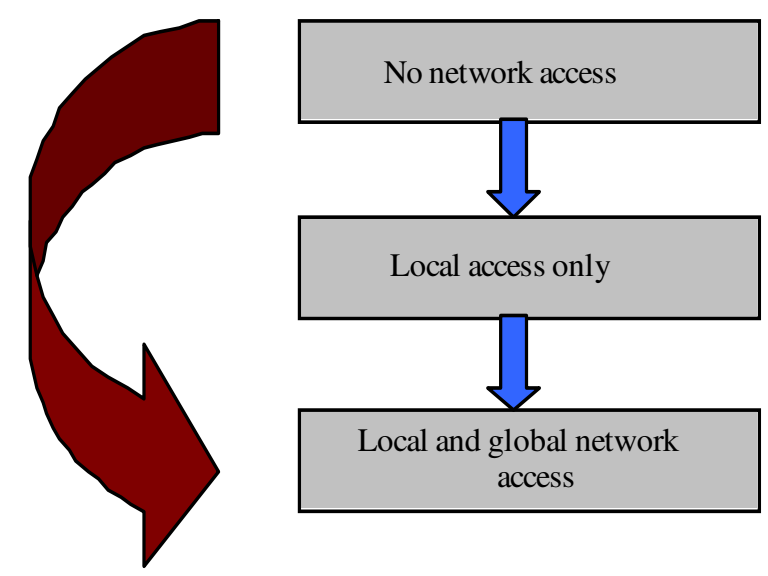

Level ofinformation access

Fig. 1: Relationship between information accessibility and type of network access

Table 1: Society response to ICT

\begin{tabular}{lll}
\hline$\varepsilon$ (ICT influence factor) & $\sigma$ (Corrective ICT factor) & $\mathrm{k}$ \\
\hline$\rightarrow 0$ & $\rightarrow 0$ & $\rightarrow 0.0$ \\
$\rightarrow 0$ & $\rightarrow 1$ & $\rightarrow 0.0$ \\
$\rightarrow 1$ & $\rightarrow 0$ & $\rightarrow 1.0$ \\
$\rightarrow 1$ & $\rightarrow 1$ & $\rightarrow 0.5$ \\
\hline
\end{tabular}

not apparent (negligible) within a society, then the society is either resisting change, or fearing change, or not equipped to accommodate the influence of new technologies $(\varepsilon \rightarrow 0, \sigma \rightarrow 1)$. If however, it strongly exists $(\varepsilon \rightarrow 1)$, then there is no need for any compensation as the society in this case is fully equipped to deal with the presence of technologies ( $\sigma$ $\rightarrow 0$ ). If however, ICT needs great efforts to stamp its influence on society (some resistance and unstable economy), then corrective action to sustain ICT is needed $(\sigma \rightarrow 1)$. The developed model can also be related to the level of information accessibility and available infrastructure as shown in Fig. 1.

\section{REFERENCES}

1. Michel, A., 2003. Reexamining information systems success through the information technology professionals perspective. Sprouts: Working Papers Inform. Environ. Syst. Org., 3:122-136,URL:

http://whitepapers.zdnet.com/abstract.aspx?docid= 175278.

2. Havill, J. T. and Ludwig, L. D. Technically speaking: fostering the communication skills of computer science and mathematics students. In Proceedinds of the 38th SIGCSE Technical Symposium on Computer Science Education. SIGCSE '07. ACM Press, New York, NY, 2007;185-189,URL:

http://www.seerc.org/ieeii2007.

3. Phillip, B. and L. Nicola, 2007. Communications, technology and society-use of research seminar topics as part of an ICT learning program, Proceedings of the Informatics Education Europe II Conference, IEEII 2007:97-106, URL: http://www.seerc.org/ieeii2007/Paperindex.html.

4. Anderson, B. and K. Tracey, 2001. Digital living: The impact (or otherwise) of the Internet on everyday Life. American Behavioral Scientist, 45: 456-475, URL: www.sagepub.com.

5. Jennings, N. and E. Wartella, 2004. Technology and the Family. In: Handbook of Family Communication, Vangelisti, A.L. (Ed.). Erlbaum Associates, Mahwah, pp: 593-608, $2^{\text {nd }}$ edition.

6. Valentine, G. and S. Holloway, 2001 Technophobia: Parents and Children's Fears about Information and Communication Technologies and the Transformation of Culture and Society. In: Children, Technology and Culture: The Impacts of Technologies in Children's Everyday Lives, Hutchby, I. and J. Moran-Ellis (Eds.). Routledge, London, 58-77, $1^{\text {st }}$ edition. 
7. Ehikhamenor, F.A., 2002. Socio-economic factors in the application of information and communication technologies in Nigerian print media. American Society for Information Science and Technology, 53(7): 602-611, URL: www3.interscience..wiley.com/journal/93514716.

8. Braa, J., E. Monteiro and S. Sahay, 2004. Networks of action: Sustainable health information systems across developing countries. MIS Quarterly, 28: 337-362,URL:

http://www.misq.org/archivist/vol/no28/Issue3/vol 28n3index.html

9. Lakhani, K.R. and R.G. Wolf, 2005. Why Hackers Do What They Do: Understanding Motivation and Effort in Free/Open Source Software Projects. In: Perspectives on Free and Open Source Software, Feller, J., B. Fitzgerald, S. Hissam and K. Lakhani (Eds.). MIT Press, Cambridge, MA, ISBN-10: 0262-06246-1, ISBN-13: 978-0-262-06246-6 pp: 3$21,1^{\text {st }}$ edition.

10. Câmara, G. and F.T. Fonseca et al., 2006. Networks of innovation and the establishment of a spatial data infrastructure in Brazil. Information Technology for Development 12(4): 255-272, URL:http://eu.wiley.com/WileyCDA/WileyTitle/pr oductCd-0787994766.html

11. Rossi, M.A, 2004. Decoding the free/open source (F/OSS) software puzzle a survey of theoretical and empirical contributions. Quaderni dell'Istit. di Econ., 424 : 1-40, URL: http://www.unisi.it/lawandeconomics/students/XVI I/rossi/papers.html

12. Sagers, G.W., 2004. The influence of network governance factors on success in open source software development projects. In: 25th International Conference in Information Systems (ICIS 2004), December 12-15, Published by Association for Information Systems, USA, 427438, URL: http://aisel.isworld.org/home.asp.

13. Wilson, E.J., 2004. The Information Revolution and Developing Countries. MIT Press, Cambridge, Mass, ISBN-10:0-262-23230-8, ISBN-13:978-0262-23230-2:37-118, $1^{\text {st }}$ edition.

14. King, J., T. Bond and S. Blanford, 2002. An investigation of computer anxiety by gender and grade. Computers in Human Behavior, 18, 69-84, URL: http://www.sciencedirect.com/science.

15. van Daal, V. and P. Reitsma, 2000. Computerassisted learning to read and spell: Results from two pilot studies. Journal of Research in Reading., 23(2): 181-193, URL: http://www.blackwellpublishing.com/journal.asp?r ef=0141-0423.
16. Brown, B.A., Reveles, J.M. and Kelly, G.J., 2005. Scientific literacy and discursive identity: A theoretical framework for understanding science learning. Science Education, 8: 779-802, URL: http://www3.interscience.wiley.com/journal/32122/ home?CRETRY $=1 \&$ SRETRY $=0$.

17. Virk, B., 2004. A balancing act: Improving student online discussion participation. Int. J. Instruct. Technol, Vol 1. No. 6, ISSN 1550-6908, URL: http://www.itdl.org/Journal/Jun_04/index.htm article08.htm

18. Garrison, D. R., T. Anderson and W. Archer, 2001. Critical thinking, cognitive presence and computer conferencing in distance education. Am. J. Distance Educ., 15(1): 7-23, URL: http://www.ajde.com/Contents/vol15_1.htm.

19. Kinshuk, C.S. and L.M. Hunt, 2004. Assessing discussion forum participation: In search of quality. Int. J. Instruct, Vol 1. No. 12. ISSN 1550-6908, URL:http://www.itdl.org/Journal/Dec_04/index.ht m,article01.htm

20. Campos, M., 2004. A Constructivist method for the analysis of networked cognitive communication and the assessment of collaborative learning and knowledge building. J. Am. Learn. Networks, 8(2): 1-29, URL: http://www.sloanc.org/publications/jaln/v8n2/pdf/v8n2_campos.pdf.

21. Spatariu, A., K. Hartley and L.D. Bendixen, 2004. Defining and measuring quality in on-line discussion. Journal of Interactive Online Learning., 2(4): 1-15, URL: http://www.ncolr.org/jiol/issues/PDF/2.4.2.pdf.

22. Câmara, G. and F.T. Fonseca, 2007. Information policies and open source software in developing countries. Journal of the American Society for Information Science and Technology, 12(4): 255272 ,

URL: http://www.asis.org/Publications/JASIS/tocs.htm .

23. Couldry, N., 2004. The Digital Divide. Web Studies. 2nd Edition. Published by Arnold, London, 185-195.

24. Slevin, J., 2000. The Internet and Society. Blackwell Publishers Ltd., Oxford, UK, $1^{\text {st }}$ edition, ISBN: 0-7456-2086-8, ISBN: 0-7456-2087-6 (pbk),

25. Webster, F., 2002. Theories of the Information Society. 2nd Edn. Routledge, London and New York. 